\title{
Molecular and Epidemiology Data on Cystic Echinococcosis in Tunisia
}

\author{
Myriam Oudni-M'rad, Selim M'rad and \\ Hamouda Babba
}

Additional information is available at the end of the chapter

http://dx.doi.org/10.5772/60891

\begin{abstract}
Cystic echinococcosis (CE) or hydatidosis is a widespread zoonose in the world. In Tunisia, despite the deployed prevention program, CE remains a serious public health problem. With a human surgical annual incidence averaging 12.6/100000 inhabitants, Tunisia is one of the most endemic areas amongst the Mediterranean countries. Three Echinococcus species have been described: E. granulosus sensu stricto (G1 and G3 genotypes), E. canadensis, and E. equinus. $\mathrm{CE}$, which commonly starts during childhood and described as a young adult disease, may be observed at any age. The liver and the lungs are the most commonly involved organs but the cyst can occur almost anywhere in the body. In production animals, the prevalence of CE is ranged from $16.42 \%$ to $40.42 \%$ in sheep, $8.56 \%$ in cattle, $6 \%$ in dromedaries, $2.9 \%$ in goats, and $8.48 \%$ in donkeys. The elevated number of stray and semi-stray dogs and their frequent contamination by E. granulosus infected viscera is the major cause of the CE spread. A high prevalence of E. granulosus infection has been reported in Tunisian dogs ranging from $3.75 \%$ to $27.1 \%$, depending on the regions. Thus, the sanitary education concerning hydatidosis should be reinforced and efforts should be made to implement a targeted educational program.
\end{abstract}

Keywords: Cystic echinococcosis, Tunisia, molecular characterization, epidemiology, public health 


\section{Introduction}

Cystic echinococcosis (CE) or hydatidosis, caused by Echinococcus granulosus, is a widespread zoonosis in the world, especially in North African countries such as Libya, Algeria, Morocco, and Tunisia [1, 2]. Alveolar echinococcosis (AE), caused by the larval stage of E. multilocularis is extremely rare in Maghreb and only three autochthonous cases of human AE were reported in Tunisia and Morocco [3-5]. CE is of veterinary and medical importance because infection with metacestode may cause severe illness and significant socio-economic repercussions. With an annual surgical incidence (SI) averaging 12.6/100000 inhabitants [6] and approximately US\$ 10-19 million losses annually in both humans and animals [7], Tunisia is one of the most endemic areas amongst the Mediterranean countries. Neighboring countries such as Italy $(\mathrm{SI}=1.6)$, Algeria $(\mathrm{SI}=3.6-4.6)$, Morocco $(\mathrm{SI}=4.6)$, Libya $(\mathrm{SI}=4.2)$, Spain $(\mathrm{SI}=0.3)$, and France $(\mathrm{SI}=0.1)$ presented lower surgical incidence $[1,8,9]$. In the E. granulosus vital cycle the adult tapeworm lives in the intestine of some carnivores (definitive hosts), and the larval stage develops in the herbivores (intermediate hosts) and humans, essentially in the liver and lungs.

\section{Echinococcus granulosus genotyping}

E. granulosus is a complex in which four or five cryptic species are intermixed: E. granulosus sensu stricto (genotypes G1 to G3), E. equinus (genotype G4), E. ortleppi (genotype G5), E. canadensis (genotypes G6 to G10), and Echinococcus felidis (lion strain) [10-12]. The characterization of the species/genotypes responsible for human and animal hydatidosis is important in order to adapt the measures of control and prevention against this parasitic disease. Indeed, it is known that the genotype influences the life cycle patterns, the host specificity, and the pathology. Four genotypes (G1, G3, G4, and G6) have been described in Tunisia using molecular techniques such as PCR-RFLP analysis of the ribosomal DNA ITS1 fragment and mitochondrial cytochrome $\mathrm{C}$ oxidase (Cox1) or elongation factor 1-alpha (ef1a) gene sequencing (Table 1). The G1 genotype was identified in humans, sheep, cattle, and dromedaries [1316], the G3 genotype in cattle and human isolates [17], the G6 genotype in one human case and in the Southern dromedaries [13, 16], and the G4 genotype in donkeys [16]. Recently, it has been demonstrated that donkeys can be infected by two different species, E. granulosus s.s (G1 genotype) and E equinus, occurring in sympatry [16].

\begin{tabular}{|c|c|c|c|c|}
\hline Origin & No. of cysts & Gene markers & Genotype frequency (\%) & Reference \\
\hline \multirow{4}{*}{ Sheep } & 102 & ITS1 and cox1 & G1 $(100 \%)$ & [13] \\
\hline & 33 & 12s rRNA & G1 (100\%) & [18] \\
\hline & 10 & Cox1 & G1 $(100 \%)$ & [17] \\
\hline & 33 & Cox1 and ef1a & G1 $(100 \%)$ & [16] \\
\hline \multirow{2}{*}{ Cattle } & 79 & ITS1 and cox1 & G1 (100\%) & [13] \\
\hline & 4 & 12sRNA & G1 $(100 \%)$ & [18] \\
\hline
\end{tabular}




\begin{tabular}{|c|c|c|c|c|}
\hline Origin & No. of cysts & Gene markers & Genotype frequency (\%) & Reference \\
\hline & 10 & Cox1 & G1 (90\%); G3 (10\%) & [17] \\
\hline & 19 & Cox1 and ef1a & G1 $(100 \%)$ & [16] \\
\hline \multirow{4}{*}{ Human } & 50 & ITS1 and cox1 & G1 (100\%) & [13] \\
\hline & 10 & Cox1 & G1 (90\%); G3 (10\%) & [17] \\
\hline & 241 & ITS1 and cox1 & G1 $(100 \%)$ & [15] \\
\hline & 25 & Cox1 and ef1a & G1 $(100 \%)$ & [16] \\
\hline \multirow{3}{*}{ Dromedary } & 3 & ITS1 and cox1 & G6 (100\%) & [13] \\
\hline & 13 & Cox1 & G1 $(100 \%)$ & [14] \\
\hline & 11 & Cox1 and ef1a & G1 (72\%); G6 (28\%) & [16] \\
\hline Donkey & 37 & Cox1 and ef1a & G1 (40\%); G4 (60\%) & [16] \\
\hline Goat & 14 & Cox1 and ef1a & G1 $(100 \%)$ & [16] \\
\hline
\end{tabular}

Table 1. Molecular epidemiology of cystic echinococcosis in human and production animals in Tunisia.

The Tunisian situation is grossly the same as other Maghreb countries (Algeria and Libya) where the G1 and the G6 genotypes were reported in livestock and camels [19-22].

In Tunisia, the most frequent genotype associated with CE is the G1 genotype (E. granulosus sensu stricto) [13-16]. Currently, at least 43 different haplotypes were described for the Cox1 gene by molecular analysis in humans and different intermediate hosts (Genbank accession numbers: U50464, AY679144, AY679145, AY679146, KM014606-KM014644, Table 2) [13, 16]. The existence of genetic and phenotypic variants inside this genotype has been previously shown by using isoelectric-focusing techniques $[23,24]$. Regarding the host origin, it has been demonstrated that there is a slight difference of the G1 genotype in parasite populations between sheep, human, and cattle (Fst values from 0.05 to 0.15$)[16,23]$. The cysts originating from human (lung or liver) are intermediary between sheep and cattle origins as considering the genetic variability, whereas cattle and sheep isolates are slightly different [25].

\begin{tabular}{|c|c|c|c|c|c|}
\hline $\begin{array}{c}\text { GenBank accession } \\
\text { numbers }\end{array}$ & Mutation & $\begin{array}{l}\text { CO1 protein } \\
\text { mutation }\end{array}$ & Host & Cyst localisation & Reference \\
\hline U50464 & C56T & $\mathrm{A} 27 \mathrm{~V}$ & Human, Sheep, Cattle & Lung and Liver & [13] \\
\hline AY679144 & $\mathrm{T} 123 \mathrm{C}$ & None & Sheep & Liver & [13] \\
\hline AY679145 & G312A & None & Human & Lung & [13] \\
\hline AY679146 & T204G & None & Cattle & Lung & [13] \\
\hline $\begin{array}{c}\text { KM014606 to } \\
\text { KM014644 }\end{array}$ & - & - & $\begin{array}{l}\text { Camels, cattle, goat sheep, } \\
\text { human, jackals, donkey, } \\
\text { wild boar }\end{array}$ & - & {$[16]$} \\
\hline
\end{tabular}

Table 2. Molecular epidemiology and G1 genotype genetic diversity observed in Tunisia. 


\section{Human disease with special focus on pediatric hydatidosis}

The E. granulosus adult stage infects the Canidae that releases the parasite eggs in the environment through their feces. Humans are a dead-end host that do not play a role in the natural cycle of the parasite. They are contaminated by an accidental consumption of the eggs, resulting from the contact with an infected dog or through the ingestion of contaminated vegetables. Eggs result in the development of one or several unilocular hydatid cysts (Figure 1 ) that could grow up to $20 \mathrm{~cm}$ in diameter $[15,26,27]$. Because of the slow rate of cyst growth, clinical symptoms do not usually arise until several years after infection. The liver and the lungs are the most commonly involved organs but the cyst can occur almost anywhere in the body.
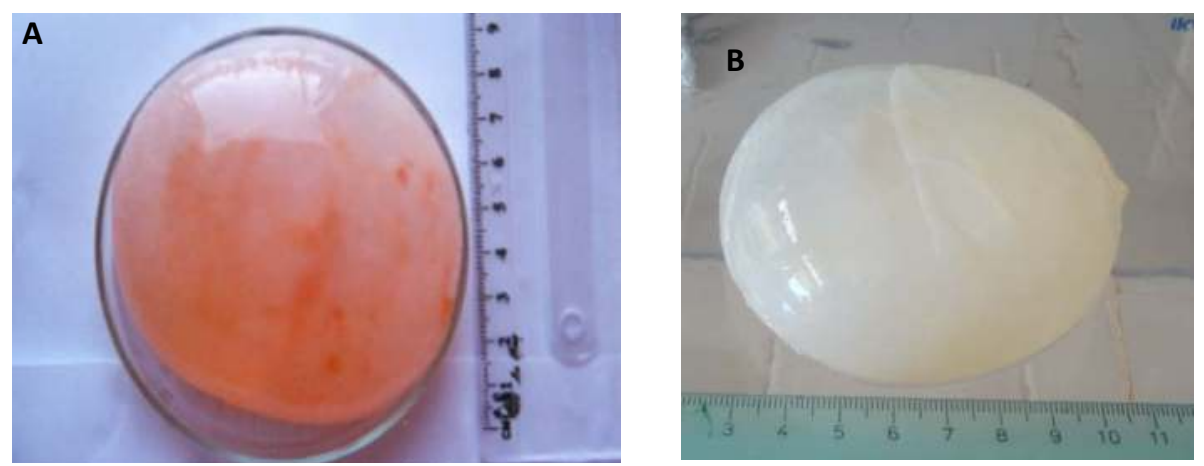

Figure 1. Hydatid cysts from Tunisian children operated at F. Bourguiba Monastir teaching hospital. A: Pulmonary cyst from an eight-year-old child. B: Hepatic cyst from a six-year-old child. Photograph: LP3M: Laboratory of Medical and Molecular Parasitology-Mycology, Faculty of Pharmacy, University of Monastir, Tunisia.

CE remains an important public health problem in Tunisia and despite the deployed prevention program, a slight reduction in the mean annual surgical incidence rate (SI) from 15 to 12.6 cases/100,000 inhabitants was observed during the last 20 years $[6,28]$. The endemic status differs from one region to another, based on the SI, and some areas have been defined as hyperendemic (SI $>22.6)$, holoendemic $(15<\mathrm{SI}<22.6)$, mesoendemic $(7.5<\mathrm{SI}<15)$, and hypoendemic regions $(\mathrm{SI}<7.5)$ [6]. The geographical repartition of different endemic regions was shown in Figure 2. Hydatidosis is known to be more important in rural areas where the definitive hosts (domestic and wild Canid) and herbivore intermediate hosts are in close contact, but an extension in the urban zones was noted during the past decade.

In Tunisia, several human studies were focusing on pediatric hydatidosis [15, 27, 29-31]. Cystic echinococcosis, which commonly starts during childhood or adolescence and described as a young adult disease, may be observed at any age. Two studies on children hydatid cysts (161 and 241 cysts) were carried out between 1999 and 2009 and assessed that the greatest number of cases was observed in the age groups of 4-9 years [15, 31]. Another retrospective study conducted between 1985 and 2009 and based exclusively on 757 pulmonary cysts of young 

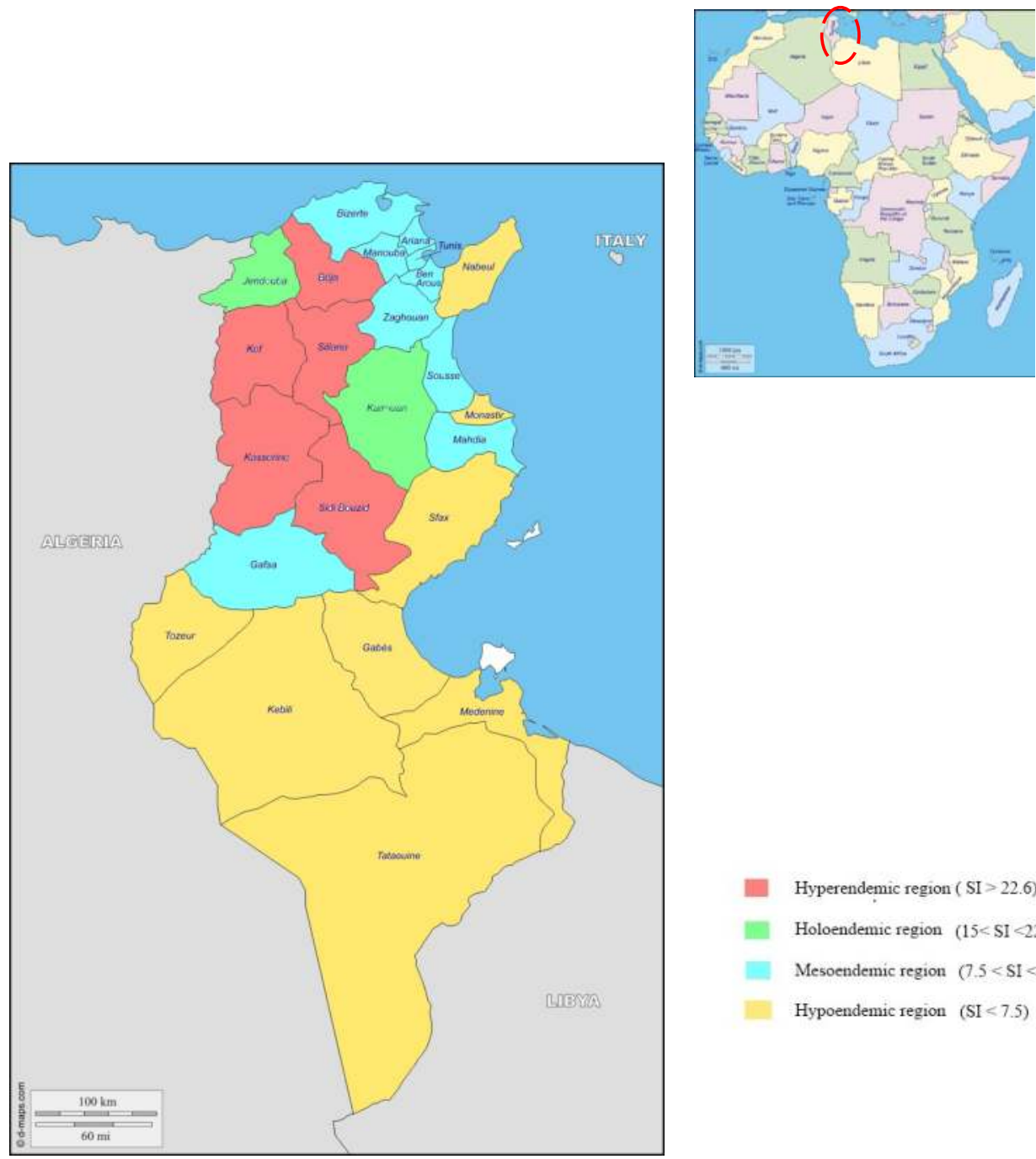

Hyperendemic region ( $\mathrm{SI}>22.6$ )

Holoendemic region $(15<\mathrm{SI}<22.6)$

Mesoendemic region $(7.5<\mathrm{SI}<15)$

Hypoendemic region $(\mathrm{SI}<7.5)$

Figure 2. Hydatidosis endemic status based on mean human annual surgical incidence (SI) published by [6]. (The maps of Africa and Tunisia come from http://d-maps.com/).

children (3-7 years) and older children (8-15 years) demonstrated a mean age of 5.7 and 12 years old, respectively [27]. This early infestation has already been described in Turkey [32], Palestine [33], and Jordan [34].

In children, the lungs are the most common sites for hydatid cysts followed by the liver (Table 3) $[15,27,31]$. This could be explained by noisier and earlier symptoms in children where cough, chest pain, and hemoptysis are the most frequently encountered signs [27, 30]. Some 
exceptional cyst localizations (central nervous system, orbit, spleen, kidney, and heart) were also described $[15,35,36]$. Several organs may be contaminated simultaneously and about $20 \%$ of cases reported in literature were involved in multiple cysts with essentially liver associated with lung $[15,27]$. The growth of the hydatid is independent of children's age since cysts of high diameter $(15 \mathrm{~cm})$ were found in children of 4 years old [15, 31].

\begin{tabular}{|c|c|c|c|c|c|c|}
\hline No. of patients & No. of cysts & Cyst localization & Frequency (\%) & Fertility (\%) & Viability (\%) & Reference \\
\hline & & Liver & 34.8 & 68.5 & & \\
\hline \multirow[t]{3}{*}{195} & 241 & Lung & 61.8 & 83 & 77 & [15] \\
\hline & & Other & 3.4 & 71 & & \\
\hline & & Lung & 59.5 & 70 & & \\
\hline \multirow[t]{2}{*}{121} & 161 & Liver & 36 & 81.5 & 79 & [31] \\
\hline & & Other & 4.5 & 71 & & \\
\hline
\end{tabular}

Table 3. CE prevalence, cyst fertility, and protoscoleces viability in Tunisian children.

Numerous pediatric studies have noted a slight male predominance compared to girls with a sex ratio of 1.2 to 1.8 [15, 27, 28, 31]. This observation was although reported in Algeria [37], Iran [38], Bulgaria [39], and Jordan [34]. The higher infestation of boys compared to girls in endemic countries is explained by the fact that school-age boys have more external activities than girls, with a greater promiscuity with dogs. In adults, in contrast to what is observed in children, women are more commonly affected than men [28, 40,41]. This difference is due to their role in the home activities and that in rural areas, the women are more often at home and care very often for dogs and cattle, which increases the risk of contamination. In addition, the adult females have more regular medical follow-up (e.g., during pregnancy) that results in fortuitous cyst discoveries on ultrasound examinations.

The direct examination of the cyst allows studying its fertility (presence or absence of protoscoleces) and the protoscolex viability. The cyst fertility was analyzed by light microscopic observation. Protoscolex viability was determined using vital eosin $0.2 \%$ coloration (Figure 3 ). The fertility of the cyst is independent of its location and its size and no relation with the age of infected children was noticed (Table 3) [15, 27, 42]. The cyst fertility and protoscoleces viability in humans are not involved in the maintenance of the parasite life cycle because human is a dead-end host but they are parameters attesting of the perfect adaptation of the parasite to humans.

As mentioned before in the genotyping section, the most frequent species associated with human hydatidosis is the E. granulosus sensu stricto (G1 genotype). Nevertheless, for two children, the E. granulosus sensu stricto (G3 genotype) and the E. canadensis species were observed. The fact that humans could be infected by different species/genotypes is an epidemiological feature to be taken into account in CE control measures. 


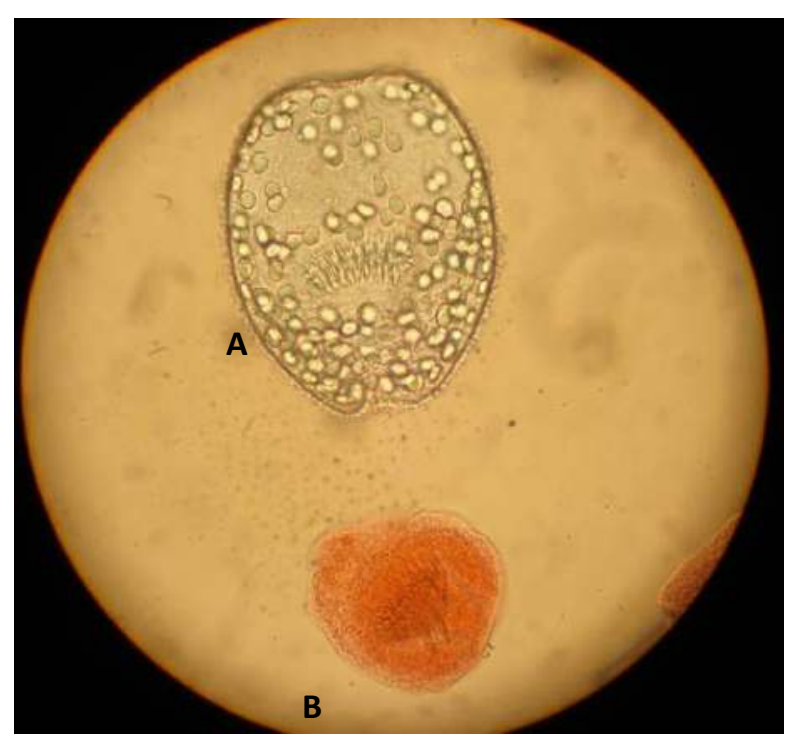

Figure 3. Determination of protoscolex viability by using $0.2 \%$ eosin coloration: Alive (A) and dead (B) protoscolex. Photograph: LP3M: Laboratory of Medical and Molecular Parasitology-Mycology, Faculty of Pharmacy, University of Monastir, Tunisia.

\section{Cystic echinococcosis in production animals}

Livestock echinococcosis leads to economic repercussions because of animal liver and lung condemnations, decrease of the carcass weight, animal fertility, and milk production [43]. In Tunisia, breeding remains mainly traditional and the population practices extensive sheep farming. Livestock are ubiquitous all over Tunisia, especially in rural areas and about 4 million sheep female unit (FU), 700,000 goat FU, 420,000 cattle FU, and 17,000 camel FU are recorded [44]. The CE prevalence in food animals depends on the presence of the intermediate host of the parasite and their close contact with the final host (stray and semistray dogs). These intermediate hosts differ from one region to another in function of climatic factors and/or breeding or alimentary practices. Thus, dromedary breeding is essentially located in Southern Tunisia (desertic climate) where camels are most consumed, whereas sheep and cattle breedings are practiced throughout the country. Herbivores acquire the infection through ingestion of echinococcus eggs excreted by the dog feces. The breeding of small animals is practiced by farmers, but also commonly practiced by households in rural and urban areas (Figures 4 and 5). The importance of pastoral animal husbandry constitutes a significant risk factor for echinococcosis transmission because of the close contact of production animals with dogs. Thus, the infected livestock that died on the pastures are not buried and dogs or other carnivores are able to access these cadavers and lead to complete the transmission cycle (Figure 6). 


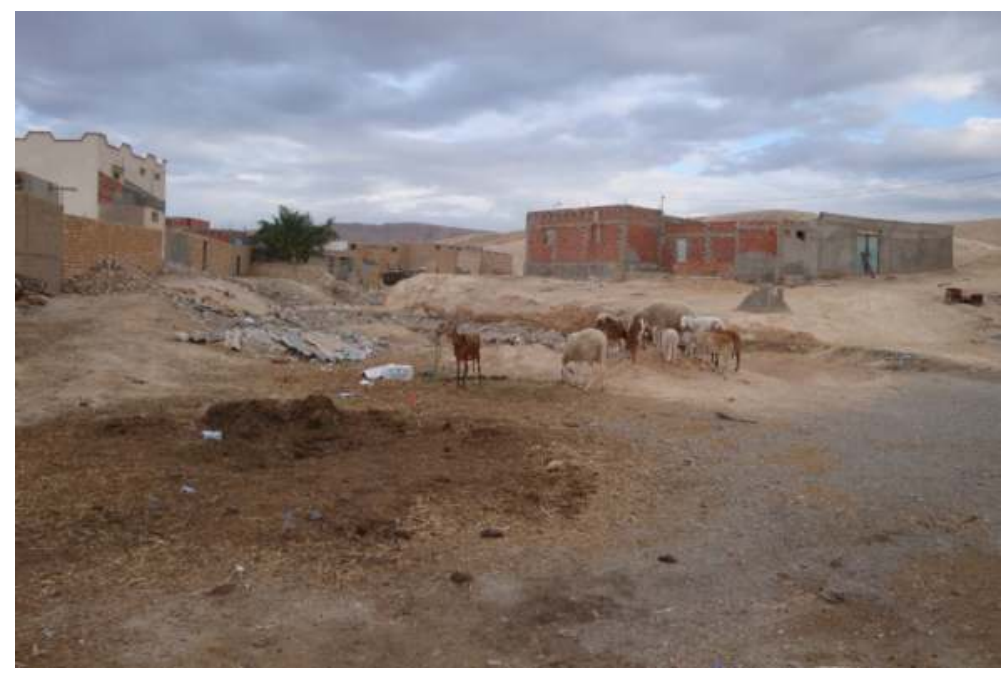

Figure 4. Pastoral sheep breeding in rural areas where sheep are in close contact with dogs. Photograph: LP3M: Laboratory of Medical and Molecular Parasitology-Mycology, Faculty of Pharmacy, University of Monastir, Tunisia.

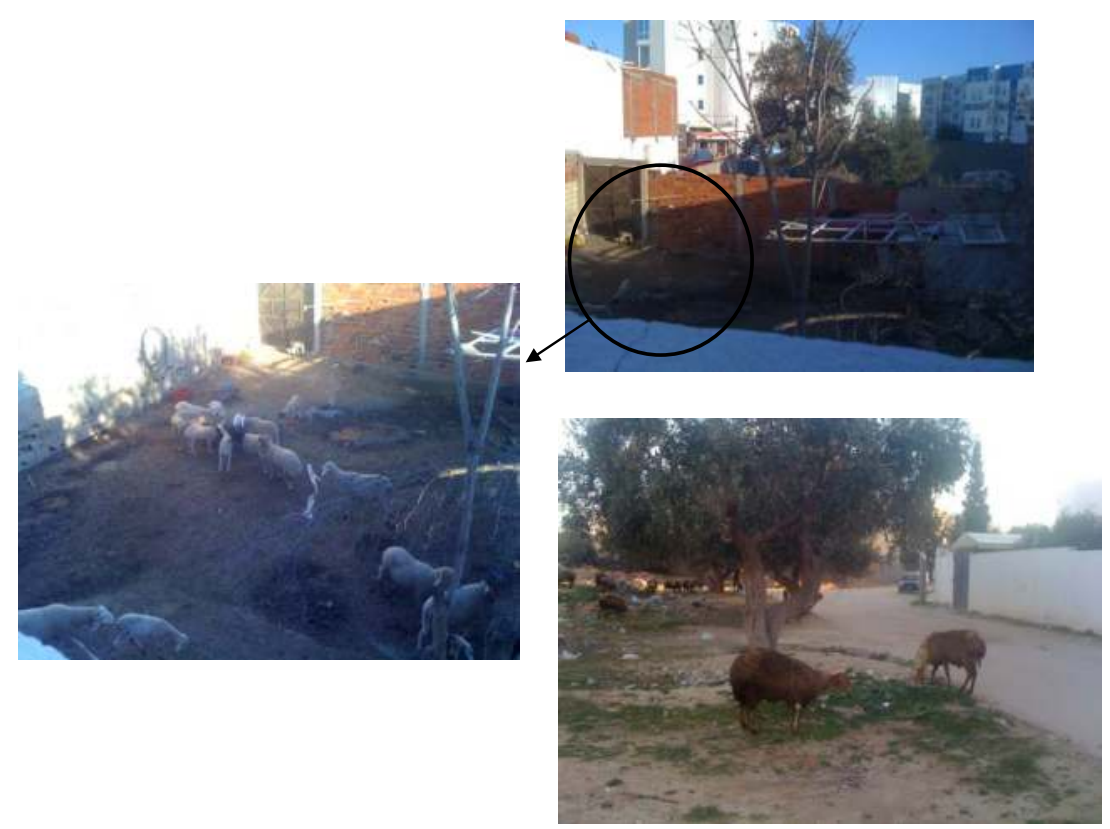

Figure 5. Sheep breeding in urban areas where sheep are in close contact with dogs. Photograph: LP3M: Laboratory of Medical and Molecular Parasitology-Mycology, Faculty of Pharmacy, University of Monastir, Tunisia. 


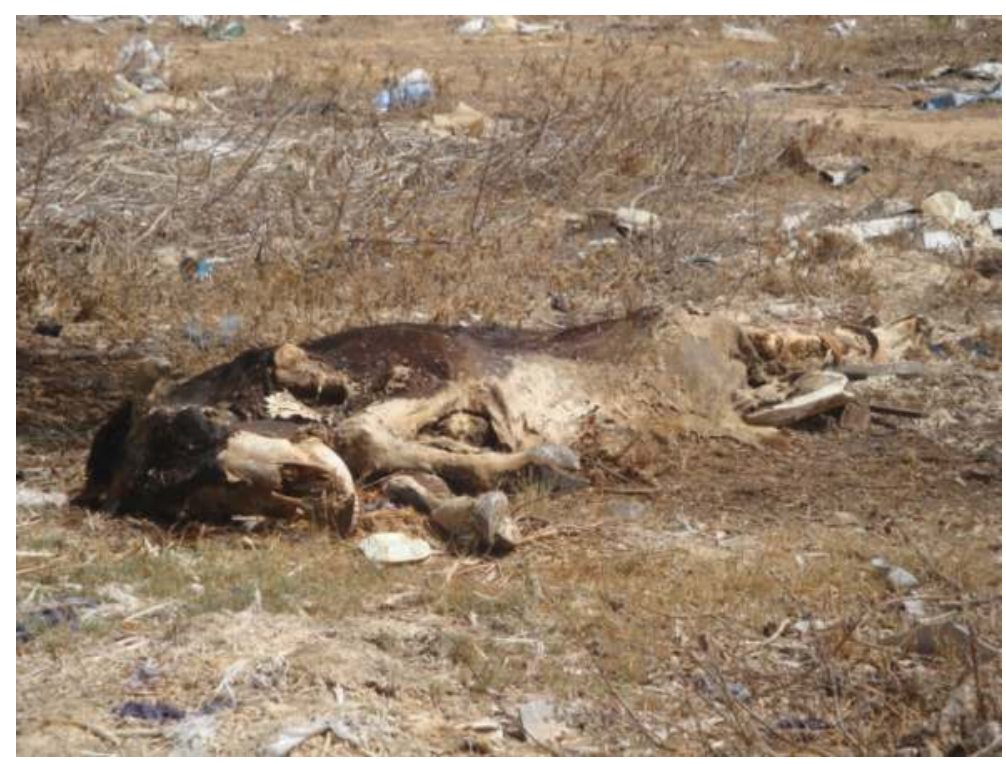

Figure 6. Carcass of dead cattle abandoned on the pasture and accessible to stray dogs. Photograph: LP3M: Laboratory of Medical and Molecular Parasitology-Mycology, Faculty of Pharmacy, University of Monastir, Tunisia.

CE prevalence in production animals was estimated by post-mortem examination of slaughtered animals at abattoirs. A series of studies carried out in Tunisia assessed that the prevalence of E. granulosus infection ranged from $16.42 \%$ to $40.42 \%$ in sheep, $8.56 \%$ in cattle, $6 \%$ in Dromedaries, $2.9 \%$ in goats, and $8.48 \%$ in donkeys [14, 45-47] (Table 4$)$. The highest prevalence was observed in sheep, as is the case in Libya (20\%) and Italy $(11.5 \%)$ [21, 48], while the lowest prevalence was noted in goats. In Morocco and Algeria, the cattle (23\%) and the camels (25\%), respectively, are the most infected animals whereas husbandry and slaughtering practices are grossly the same as in Tunisia $[19,49,50]$. It has been accepted that variations in animal CE prevalence rates can be related to the species/genotype involved in the infection [51]. Nevertheless, in Tunisia, the G1 genotype is predominant in all intermediate hosts with high fertility rates [13] and only some infection cases by others genotypes are reported (see genotyping section). Moreover, a study conducted in Tunisia has demonstrated that the sheep over 8 years old are more often contaminated than sheep of $1-2$ years and sheep of 4 years (60\% vs. $20 \%$ and $40 \%$, respectively) [46]. Consequently, in Tunisia, the difference in prevalence rate is more related to the age of slaughtered herbivores than to the species/genotype implied in the infection. In camels, the prevalence varies largely according to the region because of the difference in camel slaughtering practices. Thus, camels are slaughtered at an older age in South of Tunisia, whereas they are slaughtered at an earlier age (before 3 years) in Center of Tunisia. It has been demonstrated, in opposition to other intermediate hosts, that the camel 
cysts do not or seldom develop before the age of three [14, 52]. Therefore, it can be assumed that only old camels are implied in the parasite life cycle dog-camel.

Liver and lung are the only organs observed to be infected in production animals. The prevalence of the liver localization of the cyst was higher than that of pulmonary cysts except for the dromadaries where the pulmonary cysts are predominant (Table 4) $[14,45,46,53]$. The co-infection of both organs in the same host is frequently observed and, contrary to what is usually described in humans, several cysts (up to 50 cysts) may develop in the same organ (Figure 7).

\begin{tabular}{|c|c|c|c|c|c|c|c|c|}
\hline Hosts & $\begin{array}{c}\text { No. of } \\
\text { animals }\end{array}$ & $\begin{array}{c}\text { Prevalence } \\
(\%)\end{array}$ & $\begin{array}{l}\text { Location } \\
\text { of cysts }\end{array}$ & Frequency (\%) & Fertility & $\begin{array}{c}\text { Protoscolex } \\
\text { viability }\end{array}$ & Period & Reference \\
\hline \multirow{5}{*}{ Sheep } & \multirow{2}{*}{2722} & \multirow{2}{*}{16.42} & Liver & 54.97 & 19.24 & 74.94 & 2003-2010 & [45] \\
\hline & & & Lung & 45.02 & 11.01 & 66.49 & 2003-2010 & [45] \\
\hline & 1039 & 40.42 & liver & 40.42 & - & - & 2001-2004 & [45] \\
\hline & \multirow{2}{*}{248} & - & Liver & 67.33 & 86 & - & 2000-2005 & [53] \\
\hline & & - & Lung & 32.66 & 63 & - & $2000-2005$ & [53] \\
\hline \multirow{4}{*}{ Cattle } & \multirow{2}{*}{3913} & \multirow{2}{*}{8.56} & Liver & 62.58 & 0.55 & 67.9 & 2003-2010 & [45] \\
\hline & & & Lung & 37.41 & 0.40 & 89 & 2003-2010 & [45] \\
\hline & \multirow{2}{*}{203} & - & Liver & 60.6 & 76.5 & - & 2000-2005 & [53] \\
\hline & & - & Lung & 39.4 & 27.5 & - & 2000-2005 & [53] \\
\hline \multirow{2}{*}{ Goat } & \multirow{2}{*}{3779} & \multirow{2}{*}{2.88} & Liver & 67.82 & 15.57 & 25.63 & $2003-2010$ & [45] \\
\hline & & & Lung & 32.14 & 14.75 & 14.8 & $2003-2010$ & [45] \\
\hline \multirow{5}{*}{$\begin{array}{l}\text { Dromed- } \\
\text { aries }\end{array}$} & \multirow{2}{*}{404} & \multirow{2}{*}{5.94} & Liver & 86.27 & 22.22 & 65.86 & $2003-2010$ & [45] \\
\hline & & & Lung & 13.72 & 22.22 & 13.72 & $2003-2010$ & [45] \\
\hline & \multirow{2}{*}{291} & \multirow{2}{*}{6.5} & Liver & 7.69 & - & - & - & [14] \\
\hline & & & Lung & 92.30 & - & - & - & [14] \\
\hline & 8 & - & - & - & 100 & 100 & 2000-2005 & [53] \\
\hline \multirow{2}{*}{ Donkey } & \multirow{2}{*}{2040} & \multirow{2}{*}{8.48} & Liver & 89.9 & 3.58 & 35.80 & $\begin{array}{c}2006-2007 \text { and } \\
2009\end{array}$ & [47] \\
\hline & & & Lung & 10.09 & 15.38 & 32.96 & $\begin{array}{c}2006-2007 \text { and } \\
2009\end{array}$ & [47] \\
\hline
\end{tabular}

Table 4. CE prevalence and epidemiological data in Tunisian production animals.

However, available CE prevalence in livestock species does not reflect the real endemic situation since it is not considered private or illegal slaughtering. Uncontrolled home slaughtering during religious or local festivities is very common in Tunisia and the infected viscera 

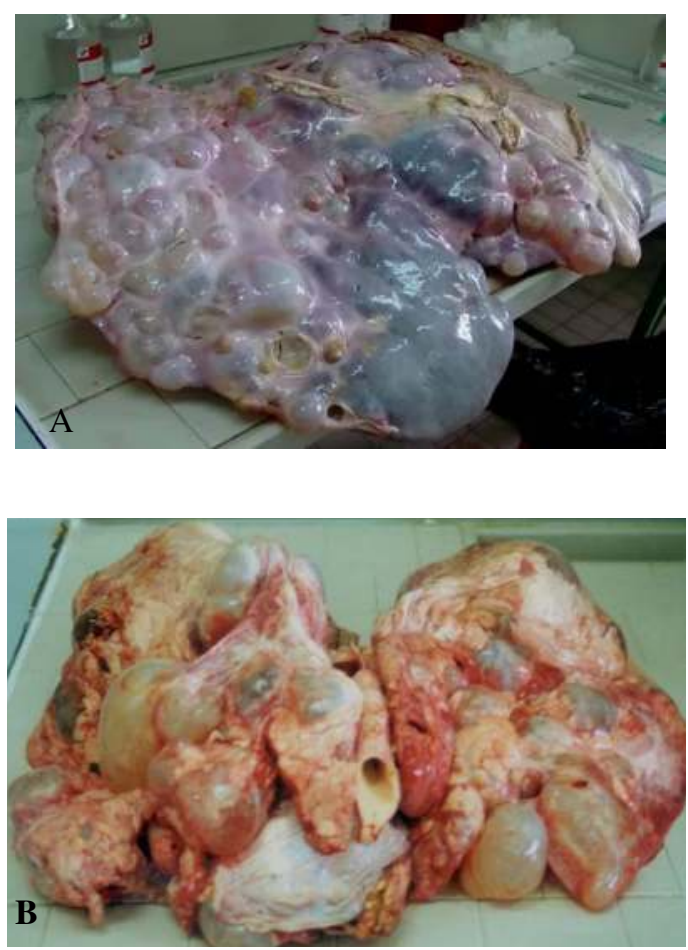

Figure 7. Multiple hydatid cysts in the liver (A) and lungs (B) of a bovine. Photograph: LP3M: Laboratory of Medical and Molecular Parasitology-Mycology, Faculty of Pharmacy, University of Monastir, Tunisia.

unsuitable for consumption are rejected and eaten by dogs. The knowledge of the parasite cycle and its transmission modalities are weak, in spite of a perception of the risk notably in rural areas. For example, a study conducted in 2007 (76 patients, 90 and 100 humans from urban and rural areas, respectively), has demonstrated that $40 \%$ of topics interrogated have the false notion that the humans' contamination is consecutive to the consumption of viscera containing hydatic cysts, whereas only $25.8 \%$ among them incriminate the dog [54]. The livestock trade in Tunisia is mainly based on weekly markets and exchange of animals all over the country. Thus, the lack of information on the exact geographical origin of livestock makes very difficult the identification of grazing areas at risk and the targeting of prophylactic measures.

Molecular analyses have demonstrated that E. granulosus species circulating in Tunisia are E. granulosus sensu stricto (G1 and G3 genotypes), E. canadensis (G6 genotype), and E. equinus (G4 genotype) $[13,16,17]$ (see Table 1 in genotyping section). The cyst fertility and the viability of protoscoleces are the main factors that allow the maintenance of the cycle between intermediate and definitive host and leads to the existence of particular life cycles. Cyst fertility varied amongst livestock host populations with average rates of $44.8 \%$ (range: $11-86 \%$ ) in sheep, $15 \%$ 
in goats, $27.13 \%$ (range: $0.4-76.5 \%$ ) in cattle, $48.5 \%$ (range: $22.22-100 \%$ ) in camels, and $4.77 \%$ in donkeys [13, 14, 45, 47, 53] (Table 4). Contrary to what was observed in European countries [48], G1 genotype has a significant fertility rate (46\%) in the cattle host in Tunisia [13] and Algeria (from $52 \%$ to $70 \%$ ) [19]. In general, a significant fertility rate, as far as cattle was concerned, was due to the E. ortleppi species (G5 genotype) and rarely to E. granulosus sensu stricto (G1 genotype) [55,56]. The findings of fertile hydatid cysts and viable protoscoleces in cattle, suggest that Tunisian and Algerian cattle can act as suitable hosts for the G1 genotype. The perfect adaptation of this genotype to bovine host is a significant parameter risk for human contamination via infected dogs and proved that cattle has more importance in the transmission cycle than previously believed.

\section{Echinococcus in dogs}

The CE is highly endemic in many North African countries and very high infection rates have been reported in dogs (55-58\% in Morocco [49], 20-25.8\% in Libya [57] and 19-42\% in Algeria [58]). In Tunisia, although a sylvatic life cycle involving wild carnivores (golden jackals and red foxes) as definitive hosts was described [59], the E. granulosus transmission is typically through a synathropic cycle between dogs and livestock (essentially sheep, cattle, and camels). In Tunisia, the dogs are used primarily to guard livestock and property. The canine population is estimated at $800,000 \mathrm{dogs}$ and composed essentially of feral and semi-feral (free-roaming dogs that are fed by an owner) dogs that rarely receive deworming treatment (Figure 8) [60].

In rural, urban, and semi-urban areas, the canine density is one dog per 3.0 to 5.5 inhabitants, one dog per 16 inhabitants and one dog per 46 inhabitants, respectively. In urban regions, less than $20 \%$ of households own a dog, whereas in rural regions there are $7-30$ dogs per $\mathrm{km}^{2}$, and more than $80 \%$ of households own at least one $\operatorname{dog}$ [61].

The prevalence of E. granulosus in dogs is estimated by several techniques including the detection of worms at necropsy, worm antigen in feces (coproantigen), or direct examination of eggs in dog feces. The prevalence of E. granulosus infection in Tunisian dogs ranges from $3.75 \%$ to $27.1 \%$ depending on the regions $[59,62,63]$ (Table 5).

\begin{tabular}{cccccc}
\hline No. of dogs & Prevalence (\%) & Worm burden (n) & Diagnostic procedure & Period & Reference \\
\hline 60 & 18.4 & 848 & Necropsy & 2007 & [59] \\
\hline 375 & 3.75 & - & Purgation & $2002-2003$ & [62] \\
\hline 256 & $6.9-27.1$ & 2534 & Necropsy & $1998-1999$ & {$[63]$} \\
\hline n: mean number of parasites per infected dog & & & \\
\hline
\end{tabular}

Table 5. Prevalence and molecular epidemiology of E. granulosus dog infection in Tunisia.

The study of the vital areas of stray dogs, based on 52 to 285 locations in a semi-urban area of Tunisia, has identified an area ranging between 0.06 and $8.53 \mathrm{~km}^{2}$ [61]. Thus, considering that 

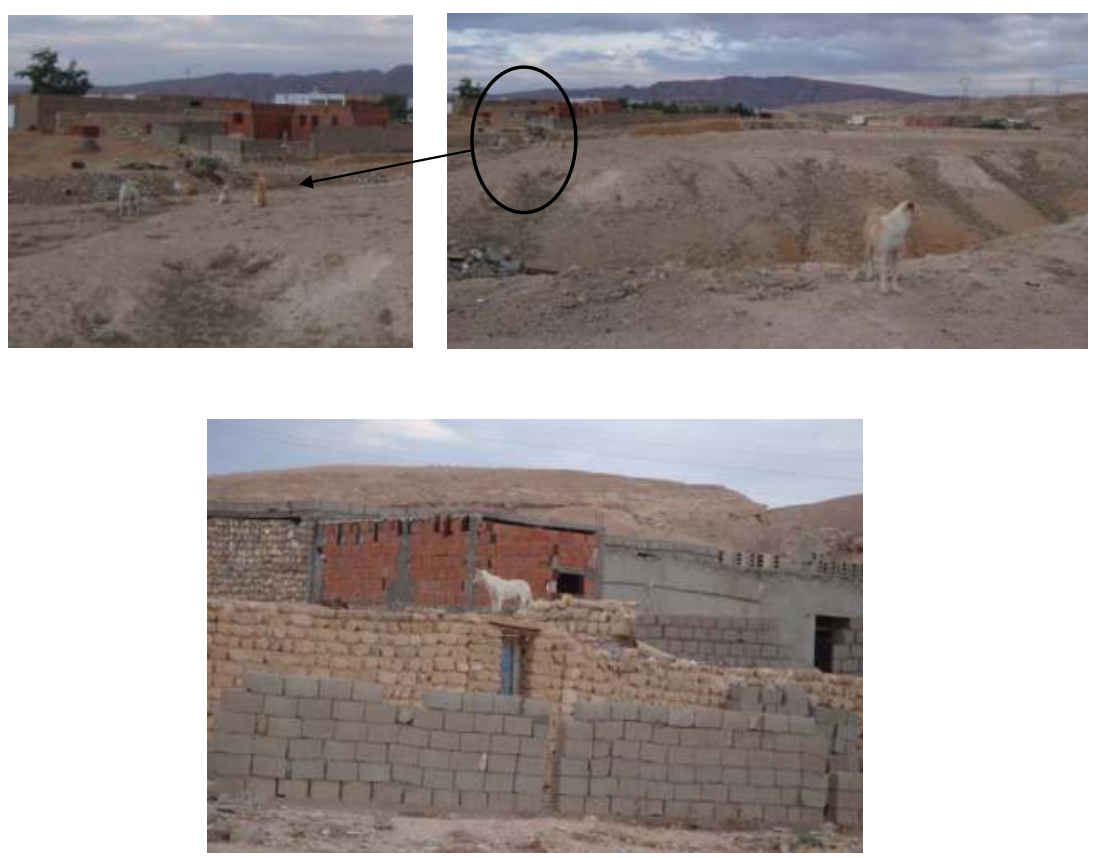

Figure 8. Stray and semi-stray dogs in rural area of Gafsa governorate (South of Tunisia). Photograph: LP3M: Laboratory of Medical and Molecular Parasitology-Mycology, Faculty of Pharmacy, University of Monastir, Tunisia.

the average number of worms per dog is estimated at several thousands [59] and more than 8,000 Echinococcus eggs were shed per day [64], dogs cause massive environmental contamination. Using direct examination of dog feces, the overall contamination index of dog feces by E. granulosus was estimated to $25.3 \%$ and was ranged between $8.3 \%$ to $41.3 \%$ depending on the regions [65]. Nevertheless, the canine echinococcosis is not necessarily correlated to human CE since transmission of echinococcus is influenced by human activities and behavior [65, 66]. As in many African countries, dog contamination is essentially due to the consumption of uninspected meat during familial or religious slaughtering, improper disposal of offal or carcasses unsuitable for consumption that are eaten by numerous stray and semi-stray dogs, and lack of knowledge about the transmission of the disease [50, 60, 67]. Thus, $38.4 \%$ and $44 \%$ of butchers and population, respectively, have an inappropriate behavior concerning the management of infected offal. They throw them directly into the trash or bury them superficially leaving them easily accessible to dogs [67].

\section{Conclusion}

Despite the control programs, essentially based on the systematic condemnation of infected offal in slaughterhouses, cystic echinococcosis remains a major public health in Tunisia. The 
endemic status differs from one region to another, and some areas have been defined as hyperendemic, holoendemic, mesoendemic, and hypoendemic regions. Hydatidosis is important in rural areas but an extension in the urban zones was noted during the past decade. The characterization of the species responsible for echinococcosis in Tunisia is a significant point that has to be taken into consideration in order to focus and to adapt the control measures. Three Echinococcus species (E. granulosus sensu stricto, E. canadensis and E. equinus) have been described in different intermediate hosts but E. granulosus sensu stricto G1 genotype remains predominant. The continuing presence of CE in Tunisia depends on a variety of factors and human behavior plays an important role in the perpetuation of the cystic echinococcosis. The importance of pastoral animal husbandry, the elevated number of unrestrained dogs, and their frequent contamination by E. granulosus infected viscera are the major causes of the CE spread. The inadequate deworming treatment, the close contact of untreated dogs with humans, and animals particularly in rural areas, the hygiene level, the poor public awareness about the disease, and the favorable ecological and climatic conditions for the survival of Echinococcus eggs in the environment constitute ideal conditions for the transmission of the infection to dogs, humans, and animals. Thus, the sanitary education concerning hydatidosis should be reinforced and efforts should be made to implement a targeted educational program. Awareness should be created for the animal attendants, farmers, customers, slaughterhouse workers, and butchers regarding the CE public health significance.

\section{Acknowledgements}

The authors thank Imen Hizem-Attig for her assistance with the linguistic part of this paper.

\section{Author details}

Myriam Oudni-M' $\operatorname{rad}^{1 *}$, Selim $\mathrm{M}^{\prime} \operatorname{rad}^{1}$ and Hamouda Babba ${ }^{1,2}$

*Address all correspondence to: myriam.mrad@gnet.tn

1 LP3M: Laboratory of Medical and Molecular Parasitology-Mycology, LR12ES08, Faculty of Pharmacy, University of Monastir, Monastir, Tunisia

2 Laboratory of Parasitology, teaching hospital F. Bourguiba, Monastir, Tunisia

\section{References}

[1] Dakkak A. Echinococcosis/hydatidosis: A severe threat in Mediterranean countries. Veterinary Parasitology 2010;174:2-11. 
[2] Sadjjadi SM. Present situation of echinococcosis in the Middle East and Arabic North Africa. Parasitology International 2006;55:197-220.

[3] Robbana M, Ben Rachid MS, Zitouna MM, Heldt N, Hafsia M. Première observation d'échinococcose alvéolaire autochtone en Tunisie. Archives Anatomo-Cytologie Pathologique 1981;29:311-312.

[4] Zitouna MM, Boubaker S, Dallagi K, Ben Safta Z, Hadj Salah H, Robbana M, Ben Rachid MS. Alveolar echinococcosis in Tunisia. A propos of 2 cases. Bulletin de la Société de Pathologie Exotique 1985;78:723-728.

[5] Maliki M, Mansouri F, Bouhamidi B, Nabih N, Bernoussi Z, Mahassini N, Elhachimi A. Hepatic alveolar hydatidosis in Morocco. Médecine tropicale: Revue du corps de santé coloniale 2004;64:379-380.

[6] Chahed MK, Bellali H, Touinsi H, Cherif R, Ben Safta Z, Essoussi M, Kilani T. Distribution of surgical hydatidosis in Tunisia, results of 2001-2005 study and trends between 1977 and 2005. Archives de l'Institut Pasteur deTunis 2010;87(1-2):43-52.

[7] Majorowski M, Carabin H, Kilani M, Ben Salah A. Echinococcosis in Tunisia: A cost analysis. Transactions of the Royal Society of Tropical Medicine and Hygiene 2005;99:268-278.

[8] WHO Regional Office for Europe, Copenhagen, Denmark. Centralized Information System for Infectious Diseases, Communicable Diseases, Surveillance and Response. http://data.euro.who.int/cisid (accessed 2014).

[9] Brundu D, Piseddu T, Stegel G, Masu G, Ledda S, Masala G. Retrospective study of human cystic echinococcosis in Italy based on the analysis of hospital discharge records between 2001 and 2012. Acta Tropica 2014;140:91-96.

[10] Hüttner M, Nakao M, Torsten W, Siefert L, Boomker JDF, Dinkel A, Sako Y, Mackenstedt U, Romig T, Ito A. Genetic characterization and Phylogenetic position of Echinococcus felidis (Cestoda : Taeniidae) from the African lion. International Journal for Parasitology 2008;8:861-868.

[11] Nakao M, McManus DP, Schantz PM, Craig PS, Ito A. A molecular phylogeny of the genus Echinococcus inferred from complete mitochondrial genomes. Parasitology 2007;134:713-722.

[12] Nakao M, Yanagida T, Okamoto M, Knapp J, Nkouawa A, Sako Y, Ito A. State-of-theart Echinococcus and Taenia: Phylogenetic taxonomy of human-pathogenic tapeworms and its application to molecular diagnosis. Infection Genetic and Evolution 2010;10(4):444-452.

[13] M'rad S, Filisetti D, Oudni M, Mekki M, Belguith M, Nouri A, Sayadi T, Lahmar S, Candolfi E, Azaiez R, Mezhoud H, Babba H. Molecular evidence of ovine (G1) and camel (G6) strains of Echinococcus granulosus in Tunisia and putative role of cattle in human contamination. Veterinary Parasitolology 2005;129:267-272. 
[14] Lahmar S, Debbek H, Zhang LH, McManus DP, Souissi A, Chelly S, Torgerson PR. Transmission dynamics of the Echinococcus granulosus sheep-dog strain (G1 genotype) in camels in Tunisia. Veterinary Parasitolology 2004;121:151-156.

[15] M'rad S, Oudni-M'rad M, Boubaker G, Bouazzi L, Gorcii M, Nouri A, Mezhoud H, Babba H. Etude rétrospective de la distribution et de la fertilité des kystes hydatiques chez l'enfant en Tunisie. Pathologie Biologie 2012;60:166-169.

[16] Boufana B, Lahmar S, Rebaï W, Ben Safta Z, Jebabli L, Ammar A, Kachti M, Aouadi S, Craig PS. Genetic variability and haplotypes of Echinococcus isolates from Tunisia. Transactions of the Royal Society of Tropical Medicine and Hygiene 2014;108(11): 706-714.

[17] M'rad S, Oudni-M'rad M, Filisetti D, Mekki M, Nouri A, Sayadi T, Candolfi E, Azaiez R, Mezhoud H, Babba H. Molecular Identification of Echinococcus granulosus in Tunisia: First Record of the Buffalo Strain (G3) in Human and Bovine in the Country. The Open Veterinary Science Journal 2010;4:27-30.

[18] Farjallah S, Busi M, Mahjoub MO, Slimane BB, Said K, D’Amelio S. Molecular characterization of Echinococcus granulosus in Tunisia and Mauritania by mitochondrial rrnS gene sequencing. Parassitologia 2007;49:239-246.

[19] Bardonnet K, Benchikh-Elfegoun MC, Bart JM, Harraga S, Hannache N, Haddad S, Dumon H, Vuitton DA, Piarroux R. Cystic echinococcosis in Algeria: Cattle act as reservoirs of sheep strain and may contribute to human contamination. Veterinary Parasitology 2003;116:35-44.

[20] Maillard S, Benchikh-Elfegoun MC, Knapp J, Bart JM, Koskei P, Gottstein B, Piarroux R. Taxonomic position and geographicaldistribution of the common sheep G1 and camel G6 strains of Echinococcus granulosus in three African countries. Parasitology Research 2007;100:495-503.

[21] Tashani OA, Zhang LH, Boufana B, Jegi A, McManus DP. Epidemiology and strain characteristics of Echinococcus granulosus in the Benghazi area of eastern Libya. Annals of Tropical Medicine and Parasitology 2002;96:369-381.

[22] Abushhewa MH, Abushhiwa MHS, Nolan MJ, Jex AR, Campbell BE, Jabbar A, Gasser RB. Genetic classification of Echinococcus granulosus cysts from humans, cattle and camels in Libya using mutation scanning-based analysis of mitochondrial loci. Molecular and Cellular Probes 2010;24:346-351.

[23] Oudni-M'rad M, M'rad S, Mekki M, Belguith M, Cabaret J, Pratlong F, Sayadi T, Nouri A, Mezhoud H, Babba H, Azaiez R. Genetic relationships between sheep, cattle and human Echinococcus infection in Tunisia. Veterinary Parasitology 2004;121:95103.

[24] Oudni-M'rad M, Cabaret J, M'rad S, Bouzid W, Mekki M, Belguith M, Sayadi T, Nouri A, Lahmar S, Azaiez R, Mezhoud H, Babba H. Genetic difference between Tu- 
nisian camel and sheep strains of the cestode Echinococcus granulosus revealed by SSCP. Parasite 2006;13:131-136.

[25] Oudni-M'rad M, Cabaret J, M'rad S, Mekki M, Belguith M, Sayadi T, Nouri A, Mezhoud H, Babba H. P-33. Echinococcus granulosus G1 genotype in three hosts (sheep, cattle and man) in Tunisia: Same or several? Proceedings of the International Symposium, Innovation for the Management of Echinococcosis, March 27-29, 2014, Besançon, France. Parasite 2014,;21:28.

[26] Ghedira-Besbes L, Haddad S, Ben Meriem C, Hammami S, Nouri A, Gueddiche MN. Giant hydatid lung cysts: About two paediatric cases. Respiratory Medicine 2010;3:174-178.

[27] Marghli A, Zairi S, Ammar J, Mohamed J, Ouerghi S, Boudaya MS, Smati B, Hamzaoui A, Kilani T. Pulmonary hydatidosis: A single-center study comparing older and small children. Journal de pédiatrie et de puériculture 2012;25:81-90.

[28] Ministère de la Santé Publique. Incidence chirurgicale de l'hydatidose en Tunisie: 1988-1992. Rapport interne de la D.S.S.B: Direction des soins de santé de base 1993.

[29] Chaouachi B, Nouri A, Ben Salah S, Lakhoua R, Saied H. Les kystes hydatiques du poumon chez l'enfant. À propos de 643 cas. Pédiatrie 1988;43:769-773.

[30] Chaouachi B, Ben Salah S, Lakhoua R, Hammou A, Gharbi HA, Saied H. Les kystes hydatiques chez l'enfant. Aspects diagnostiques et thérapeutiques. A propos de 1195 cas. Annales de pédiatrie 1989;36:441-449.

[31] Oudni-M'rad M, M'rad S, Gorcii M, Mekki M, Belguith M, Harrabi I, Nouri A, Azaiez R, Mezhoud H, Babba H. L'échinococcose hydatique de l'enfant en Tunisie: Fertilité et localisation des kystes. Bulletin de la Société de Pathologie Exotique 2007;100:10-13.

[32] Anadol D, Göçmen A, Kiper N, Ôzçelik U. Hydatid disease in childhood: A retrospective analysis of 376 cases. Pediatric Pulmonology 1998;6:190-196.

[33] Abu-Hassan N, Daragmeh M, Adwan K, Al-Qaoud K, Abdel-Hafez SK. Human cystic echinococcosis in the West Bank of Palestine: surgical incidence and seroepidemiological study. Parasitology Research 2002;88:107-112.

[34] Al-Qaoud KM, Craig PS, Abdel-Hafez SK. Retrospective surgical incidence and case distribution of cystic echinococcosis in Jordan between 1994 and 2000. Acta Tropica 2003;87:207-214.

[35] Limaiem F, Bellil S, Bellil K, Chelly I, Mekni A, Khaldi M, Haouet S, Zitouna M, Kchir N. Primary hydatidosis of the central nervous system: A retrospective study of 39 Tunisian cases. Clinical Neurology and Neurosurgery 2010;112:23-28.

[36] Jeblaoui Y, Bouguila J, Yacoub K, Bouguila H, Ben Neji N, Besbes G. Orbital hydatid cyst. Revue de Stomatologie et de Chirurgie Maxillo-faciale 2008;109:117-119. 
[37] Zait H, Achir I, Guerchani MK, Hamrioui B. Profil épidémiologique de 290 cas d'échinococcose kystique humaine diagnostiqués au CHU Mustapha d'Alger (2006 à 2011). Pathologie Biologie 2013;61:193-198.

[38] Mamishi S, Sagheb S, Pourakbari B. Hydatid disease in Iranian children. Journal of Microbiology, Immunology and Infection 2007;40:428-431.

[39] Todorov T, Boeva V. Echinococcosis in children and adolescents in Bulgaria: a comparative study. Annals of Tropical Medicine and Parasitology 2000;94:134-144.

[40] Lahmar S, Rebaï W, Boufana BS, Craig PS, Ksantini R, Daghfous A, Chebbi F, Fteriche F, Bedioui H, Jouini M, Dhibi M, Makni A, Ayad MS, Ammous A, Kacem MJ, Ben Safta Z. Cystic echinococcosis in Tunisia: Analysis of hydatid cysts that have been surgically removed from patient. Annals of Tropical Medicine and Parasitology 2009;103:593-604.

[41] Bellil S, Limaiem F, Bellil K, Chelli I, Mekni A, Haouet S, Kchir N, Zitouna M. Profil épidémiologique des kystes hydatiques extra pulmonaires: A propos d'une série tunisienne de 265 cas. Tunisie Médicale 2009;87:123-126.

[42] M'rad S, Oudni-M'rad M, Chaabane-Bennaoues R, Hizem A, Bannour-Ben Abdeljelil A, Ksia A, Lamiri R, Mekki M, Nouri A, Mezhoud H, Babba H. P-32. Identification of Echinococcus granulosus species and case distribution of hydatid cysts in children in Tunisia: Proceedings of the International Symposium, Innovation for the Management of Echinococcosis, March 27-29, 2014, Besançon, France. Parasite 2014;21:28.

[43] Torgerson PR. Economics effects of echinococcosis. Acta Tropica 2003;85:113-118.

[44] Ministère de l'agriculture, Direction de la production agricole. Ressources génétiques et animales en Tunisie. Presentation presented at: A symposium; 2013 Avril 14-15; Abidjan, Côte d'Ivoire. http://www.au-ibar.org/events/au-ibar/237-the-9th-conference-of-ministers-responsible-for-livestock-in-africa?showall=\&start=1.

[45] Lahmar S, Trifi M, Ben Naceur S, Bouchhima T, Lahouar N, Lamouchi I, Maamouri N, Selmi R, Dhibi M, Torgerson PR. Cystic echinococcosis in slaughtered domestic ruminants from Tunisia. Journal of Helminthology 2013;87(3):318-325.

[46] Lahmar S, Ben Chéhida F, Petavy AF, Hammou A, Lahmar J, Ghannay A, Gharbi HA, Sarciron ME. Ultrasonographic screening for cystic echinococcosis in sheep in Tunisia. Veterinary Parasitology 2007;143:42-49.

[47] Lahmar S, Boufana B, Jebabli L, Craig PS, Ayari H, Basti T, Dhibi M, Torgerson PR. Modelling the transmission dynamics of cystic echinococcosis in donkeys of different ages from Tunisia. Veterinary Parasitology 2014;20:119-124.

[48] Cardona GA, Carmena D. A review of the global prevalence, molecular epidemiology and economics of cystic echinococcosis in production animals. Veterinary Parasitology 2013;192:10-32. 
[49] Azlaf R, Dakkak A, Chentoufi A, El Berrahmani M. Modelling the transmission of Echinococcus granulosus in dogs in the northwest and in the southwest of Morocco. Veterinary Parasitology 2007;145:297-303.

[50] Seimenis A. Overview of the epidemiological situation on echinococcosis in the Mediterranean region. Acta Tropica 2003;85:191-195.

[51] McManus DP. Molecular discrimination of taeniid cestodes. Parasitology International 2006;55:31-37.

[52] Ibrahem MM, Craig PS. Prevalence of cystic echinococcosis in camels (Camelus dromedarius) in Libya. Journal of Helminthology 1998;72:27-31.

[53] M'rad S. Etude par les techniques PCR-RFLP et séquençage du polymorphisme génétique d'Echinococcus granulosus isolé chez l'homme et l'animal en Tunisie. [PhD Thesis]. Sfax, University of Sfax; 2006.

[54] Benabid M, Chahed MK, Nouira R, Galai Y, Bouratbine A, Aoun K. Knowledge, behaviour and implications on hydatidosis. Revue Tunisienne d'Infectiologie 2007;1(4): 22-28.

[55] Thompson RC, McManus DP. Towards a taxonomic revision of the genus Echinococcus. Trends in Parasitology 2002;18:452-457.

[56] Thompson RCA, Kumaratilake LM, Eckert J. Observation on Echinococcus granulosus of cattle origin in Switzerland. International Journal for Parasitology 1984;14(3):283291.

[57] Buishi IE, Njoroge EM, Bouamra O, Craig PS. Canine echinococcosis in northwest Libya: Assessment of coproantigen ELISA, and a survey of infection with analysis of risk factors. Veterinary Parasitology 2005;130(3-4):223-232.

[58] Bentounsi B, Meradi S, Ayachi A, Cabaret J. Cestodes of Untreated Large Stray Dog Populations in Algeria: A Reservoir for Herbivore and Human Parasitic Diseases. The Open Veterinary Science Journal 2009;3:64-67.

[59] Lahmar S, Boufana B, Lahmar S, Inoubli S, Guadraoui M, Dhibi MH, Bradsha W, Craig PS. Echinococcus in the wild carnivores and stray dogs of northern Tunisia: The results of a pilot survey. Annals of Tropical Medicine and Parasitology 2009;103(4): 323-331.

[60] Aoun K, Bouratbine A. Epidemiological data concerning hydatidosis in Tunisia, Médecine et Maladies Infectieuses 2007;37:40-42.

[61] Food and Agriculture Organization of the United Nations. Renforcement de la surveillance et des systèmes d'alerte pour la fièvre catarrhale ovine, la fièvre du Nil occidental et la rage au Maroc, en Algérie et en Tunisie. 2009. 17p. Projet GCP/RAB/002/ FRA. 
[62] Lahmar S, Sarciron ME, Rouiss M, Hammouda A, Youssfi M, Mensi M. Echinococcus granulosus and other intestinal helminths in semi-stray dogs in tunisia : infection and re-infection rates. La Tunisie médicale 2008;86(3):279-286.

[63] Lahmar S, Kilani M, Torgerson PR. Frequency distribution of Echinococcus granulosus and other helminths in stray dogs in Tunisia. Annals of Tropical Medicine and Parasitology 2001;95(1):69-76.

[64] Gemmell MA, Lawson JR, Roberts MG. Population dynamics in echinococcosis and cysticercosis: Evaluation of the biological parameters of Taenia hydatigena and $\mathrm{T}$. ovis and comparison with those of Echinococcus granulosus. Parasitology 1987;94(1): 161-180.

[65] Chaabane-Banaoues R, Oudni-M'rad M, Cabaret J, M'rad S, Mezhoud H, Babba H. Infection of dogs with Echinococcus granulosus: causes and consequences in an hyperendemic area. Parasites \& Vectors 2015;8(1):231.

[66] Jenkins EJ, Schurer JM, Gesy KM. Old problems on a new playing field: Helminth zoonoses transmitted among dogs, wildlife, and people in a changing northern climate. Veterinary Parasitology 2011;182:54-69.

[67] Besbes M, Sellami H, Cheikhrouhou F, Makni F, Ayadi A. L'abattage clandestin en Tunisie: Enquête sur les connaissances et les pratiques des bouchers face à l'hydatidose. Bulletin de la Société de Pathologie Exotique 2003;96(4):320-322. 